14

\title{
Исследование влияния колхицина на нативные фибробласты методами атомно-силовой и конфокальной микроскопии
}

\author{
(C) М.М. Халисов, ${ }^{1,2}$ В.А. Пеннияйнен, ${ }^{1}$ C.А. Подзорова, ${ }^{1}$ К.И. Тимощук, ${ }^{1,2}$ А.В. Анкудинов, ${ }^{2,}$ Б.В. Крылов \\ ${ }^{1}$ Институт ффизиологии им. И.П. Павлова РАН, \\ 199034 Санкт-Петербург, Россия \\ ${ }^{2}$ Физико-технический институт им. А.Ф. Иоффре РАН, \\ 194021 Санкт-Петербург, Россия \\ ฯ e-mail: alexander.ankudinov@mail.ioffe.ru
}

Поступило в Редакцию 3 апреля 2020 г.

В окончательной редакции 3 апреля 2020 г.

Принято к публикации 3 апреля 2020 г.

Посредством методов атомно-силовой и конфокальной лазерной сканирующей микроскопии исследовано действие на первичную культуру фибробластов крысы колхицина, $1 \mu \mathrm{g} / \mathrm{ml}$, вызывающего деполимеризацию тубулиновых микротрубочек. При анализе данных атомно-силовой микроскопии скользящий тип контакта зонд-клетка выявлялся по возрастанию на ее наклонных участках кажущейся деформации. Для однозначной трактовки наблюдаемых вариаций механических характеристик фибробластов необходимо доказать скольжение зонда по поверхности клетки. Было обнаружено, что некоторые фибробласты являются мягкими и характеризуются довольно однородным распределением кажущегося модуля Юнга по своей поверхности, другие, напротив, гораздо тверже, с жесткими фибриллярными структурами на карте модуля Юнга. Показано, что колхицин вызывает достоверное упрочнение клеток в обеих группах. Данные конфокальной микроскопии позволяют заключить, что наблюдаемый эффект связан с увеличением внутриклеточного содержания $F$-актина в фибробластах.

Ключевые слова: атомно-силовая микроскопия, конфокальная лазерная сканирующая микроскопия, колхицин, фибробласты, цитоскелет.

DOI: 10.21883/JTF.2020.11.49987.118-20

\section{Введение}

Колхицин ингибирует, тормозит реакцию полимеризации тубулиновых микротрубочек - одного из основных компонентов каркаса клеток, цитоскелета. С помощью метода атомно-силовой микроскопии (АСМ) обнаружено, что, несмотря на это, данное вещество провоцирует рост жесткости (кажущегося модуля Юнга) поверхностного слоя клеток линий VERO и SMCC-7721 [1]. Такой неожиданный результат можно связать с сопутствующим деполимеризации микротрубочек увеличением внутриклеточного содержания $F$-актина и, в частности, с формированием стресс-фибрилл, зарегистрированным ранее на культуре клеток 3T3 и Rat-2 [2]. Сеть актиновых микрофиламентов - еще одна ключевая составляющая цитоскелета - считается в наибольшей степени ответственной за механические свойства клетки [3].

В методе АСМ используются зондовые датчики, представляющие собой упругую консоль (кантилевер), на конце которой находится острая игла - зонд [4]. Регистрация силового взаимодействия между зондом и исследуемой поверхностью осуществляется путем измерения углов отклонения упругой консоли. Чаще всего ее отклонения определяются посредством схемы оптического рычага [5]. В такой схеме измеряются лишь два параметра: угол изгиба и угол кручения консоли в точке фокуса лазерного луча, как правило, устанавливаемой на конце кантилевера, в то время как вектор смещения и приложенной силы имеет три компоненты. Поскольку угол изгиба определяется по наклону лишь в одной точке АСМ-кантилевера, невозможно распознать аномальный прогиб консоли [6-8], который, в свою очередь, может служить причиной ошибочных измерений амплитуды, направления силы взаимодействия и, как следствие, сигнала контактной жесткости. АСМ-измерения в условиях сильного трения в контакте трактуются неоднозначно. В частности, рост сигнала жесткости из-за какого-то внешнего фактора можно объяснить как реальным упрочнением объекта, так и уменьшением трения в контакте. В работах $[9,10]$ нативные клетки классифицировались по преобладанию вклада нормальных или латеральных сил в контакте зонд-объект в изгиб консоли. Было показано, что рост кажущейся деформации на наклонных участках однородного образца свидетельствует о проскальзывании на нем АСМ-зонда. Наблюдение данного эффекта позволяет пренебрегать вкладом латеральной компоненты силы в контакте зонд-образец по сравнению с нормальной и использовать значения контактной жесткости (либо деформации) для количественной диагностики образца.

В работе [1] было зарегистрировано, что в отличие от упомянутых клеток VERO и SMCC-7721 на клетки HL-7702 колхицин практически не влияет. При трактовке этого результата вышеупомянутая проблема 
ACМ-измерений не учитывалась. Кроме того, авторы не применяли конфокальную микроскопию для установления связи упрочнения клеток с ростом количества $F$-актина.

В настоящей работе действие колхицина на первичную культуру фибробластов крысы было изучено посредством АСМ с использованием методики работ $[9,10]$, а также метода конфокальной лазерной сканирующей микроскопии (КЛСМ).

\section{1. Методы исследования}

Первичную культуру фибробластов для исследования методами АСМ и КЛСМ выделяли из сердца новорожденных крысят линии Wistar. Отделяли предсердия от желудочков, затем фибробласты изолировали из последних путем ферментативной обработки в $0.125 \%$ растворе трипсина (Sigma, США) с последующим механическим выделением клеток при $4^{\circ} \mathrm{C}$. Полученную клеточную суспензию вводили в питательную среду следующего содержания: 45\% раствора Хенкса, 40\% среды Игла, $10 \%$ фетальной сыворотки коровы, $0.5 \mathrm{U} / \mathrm{ml}$ инсулина, $0.6 \%$ глюкозы, $2 \mathrm{mM}$ глютамина и $100 \mathrm{U} / \mathrm{ml}$ гентамицина. Изолированные фибробласты помещали в $40 \mathrm{~mm}$ чашки Петри, дно которых было предварительно покрыто коллагеном для лучшей адгезии клеток и культивировали в течение 5 суток при $36.5^{\circ} \mathrm{C}$ и $5 \%$ углекислого газа в $\mathrm{CO}_{2}$-инкубаторе (Sanyo, Япония). Колхицин в концентрации $1 \mu \mathrm{g} / \mathrm{ml}$ добавляли в культуральную среду за $24 \mathrm{~h}$ до эксперимента. Контрольные фибробласты культивировали без колхицина, в питательной среде стандартного содержания.

Для визуализации цитоскелета фибробластов использовали фаллоидин, конъюгированный с флуоресцентным красителем Texas Red (Life Technologies, США). F-актин в фибробластах окрашивали рабочим раствором Texas Red®-X phalloidin в концентрации $3 \mu \mathrm{l} / \mathrm{ml}$ в течение $1 \mathrm{~h}$. Дополнительно ядра клеток окрашивали 1\% раствором специфического флуоресцентного красителя DAPI (Life Technologies, CША) в течение $10 \mathrm{~min}$. Краситель Техаs $\operatorname{Red}$ возбуждали излучением с длиной волны $\lambda=591 \mathrm{~nm}$ и регистрировали свечение красителя в красной области спектра (он флуоресцирует на длине волны $\lambda=608 \mathrm{~nm}$ ). Флуоресценцию DAPI возбуждали диодным лазером с $\lambda=405 \mathrm{~nm}$, регистрируя флуоресценцию в диапазоне $\lambda=450-490 \mathrm{~nm}$.

Изучение механических характеристик фибробластов проводилось с помощью атомно-силового микроскопа BioScope Catalyst (Bruker, США), объединенного с инвертированным оптическим микроскопом Ахіо Observer Z1 (Carl Zeiss, Германия). Оптический микроскоп служил для выбора объектов АСМ-сканирования и отслеживания состояния исследуемых клеток во время визуализации посредством зондового микроскопа. АСМ-наноиндентирование фибробластов осуществлялось в физиологически-адекватных условиях: прямо в чашке Петри с питательной средой при постоянной температуре $\left(\approx 37^{\circ} \mathrm{C}\right)$. Поддержание температуры обеспечивал встроенный в атомно-силовой микроскоп нагревательный элемент под управлением термоконтроллера модели 335 (Lake Shore Cryotronics, США).

Измерения проводились в режиме АCM PeakForce QNM, позволяющем одновременно визуализировать топографию клетки и картировать ее механические характеристики, такие как сигналы деформации и кажущегося модуля Юнга. Определение локальных деформации и модуля Юнга основано на автоматизированном анализе силовых кривых (зависимостей силы взаимодействия от расстояния зонд-образец), производимом в режиме PeakForce QNM прямо во время сканирования образца.

Для индентирования фибробластов использовали зонды CSG10 (НT-МДТ СИ, Россия). Перед исследованием клеток коэффициент жесткости каждого кантилевера калибровали на воздухе по методу тепловых шумов. Поскольку в экспериментах использовались стандартные острые зонды, расчет модуля Юнга производили по модели Снеддона, подразумевающей аппроксимацию острой вершины зонда конусом [11]. Сканировали квадратные области со стороной от 40 до $70 \mu \mathrm{m}$ в зависимости от размера фибробласта. При этом, как правило, АСМ-кадр содержал бо́льшую часть клетки, некоторые фрагменты периферии фибробласта в кадр не попадали из-за значительной протяженности исследуемого объекта в плоскости $X Y$.

Сканирование фибробластов в режиме PeakForce QNM производилось с частотой строчной развертки $0.15 \mathrm{~Hz}$ и размером АСМ-кадра $128 \times 128$ точек. Заданная величина пиковой силы была выбрана равной $3 \mathrm{nN}$, а амплитуда и частота вертикального зондирования $1 \mu \mathrm{m}$ и $0.25 \mathrm{kHz}$ соответственно.

Для исследования действия колхицина на механические характеристики фибробластов использовали сигнал кажущегося модуля Юнга, см. подробнее [9]. На АСМ-карте этого сигнала выделяли всю попавшую в кадр часть клетки за исключением краев, где толщина фибробласта может быть недостаточной для корректных измерений из-за влияния твердой подложки. Каждую клетку характеризовали средним значением параметра, определенным в рамках выделенной области. Для выявления реакции фибробластов на колхицин вычисляли усредненные значения модуля Юнга для групп клеток: подвергшихся действию колхицина и контрольных фибробластов.

Обработка полученных экспериментальных АСМ-данных осуществлялась с помощью программ для визуализации и анализа данных сканирующей зондовой микроскопии NanoScope Analysis v1.40 (Bruker, США) и Gwyddion 2.55 (свободное программное обеспечение).

Для цитологического анализа использовали конфокальный лазерный сканирующий микроскоп LSM 710 (Carl Zeiss, Германия) в комплексе с инвертированным оптическим микроскопом Axio Observer Z1 (Carl 
Zeiss, Германия). Интенсивность флуоресценции измерялась по прямоугольным областям, площадь выбранного участка клетки во всех случаях была одинаковой. При этом область анализа выбирались так, что в ее рамках функция распределения интенсивности характеризовалась нормальным распределением. Для каждого фибробласта было сделано по три измерения интенсивности. При оценке количества фибриллярного актина определяли усредненную интенсивность флуоресценции каждой клетки, которую оценивали в условных единицах (а.u.). Для обработки экспериментальных данных был использован аппаратно-программный комплекс для визуализации, анализа и хранения изображений ZEN_2012 конфокального лазерного сканирующего микроскопа LSM-710 (Carl Zeiss, Германия). Статистический анализ проводили с помощью программы STATISTICA $8.0 \mathrm{c}$ применением $t$-критерия Стьюдента.

\section{2. Результаты и обсуждение}

Исследование механических характеристик фибробластов с помощью АСМ показало, что под действием колхицина, $1 \mu \mathrm{g} / \mathrm{ml}$, клетки становятся жестче. Культивированные в присутствии изучаемого вещества фибробласты имели средний кажущийся модуль Юнга $54 \pm 39 \mathrm{kPa}$ $(n=50)$, в то время как контрольные клетки демонстрировали меньшее значение параметра $-35 \pm 20 \mathrm{kPa}$ $(n=49)$. Полученное различие статистически значимо по $U$-критерию Манна-Уитни $(p<0.05)[12]$.

Для достоверности этого результата необходимо доказать, что АСМ-зонд проскальзывает на поверхности клетки при ее продавливании. В противном случае, как было отмечено ранее $[9,10]$, он трактуется неоднозначно, и регистрируемое увеличение сигнала может на самом деле быть связано не с ростом модуля Юнга объекта исследования, а с падением трения в контакте зонд-клетка. Поэтому у исследованных фибробластов были проанализированы признаки скользящего контакта зонд-клетка - максимумы деформации на границах изучаемых объектов. В связи с особенностями АСМ-визуализации клеток, когда зонд попадает с подложки на клетку, в сигнале деформации можно наблюдать скачок из-за резкого увеличения нагрузки со стороны зонда на клетку. Вследствие ограниченной скорости обратной связи, заданная пиковая сила $3 \mathrm{nN}$ установиться не успевает. Во время сканирования значение пиковой силы в момент подъема на клетку может быть заметно больше, а при спуске - меньше, чем $3 \mathrm{nN}$. Предполагая, что деформация пропорциональна силе, можно скорректировать этот методический вклад и перенормировать экспериментальные значения деформации фибробластов, используя следующее выражение:

$$
D_{C}=D_{E} \frac{F_{S P}}{F_{S P}+F_{E}},
$$

где $D_{C}$ и $D_{E}-$ скорректированное и экспериментальное локальные значения деформации соответственно, $F_{S P}-$ заданное значение пиковой силы $(3 \mathrm{nN})$, a $F_{E}$ - локальная ошибка силы.

Пример коррекции АСМ-данных деформации фибробласта приведен на рис. $1, a, b, d$. Скорректированное изображение (рис. $1, b)$ в итоге представляет собой АCM-карту деформации фибробласта при пиковой силе $3 \mathrm{nN}$ в каждой точке индентирования. Обратим внимание, что после коррекции всплеск деформации на восходящем склоне фибробласта не исчез полностью, а лишь уменьшился по амплитуде (данный максимум помечен стрелкой в верхнем правом углу рис. $1, d)$. Таким образом, нельзя объяснить скачок, наблюдаемый в сигнале экспериментальной деформации, лишь ошибкой регулирования силы взаимодействия. Такая деформация кажущаяся, она проявляет соскальзывание острия зонда на наклоне, на границе клетки $[9,10]$. Отметим, что максимум в сигнале скорректированной деформации и соответственно соскальзывание зонда с клетки наблюдается и на крутом нисходящем склоне фибробласта (обозначен стрелкой в верхнем левом углу рис. $1, d$ ).

Фибробласты с признаками соскальзывания зонда на склонах клетки отбирали, анализируя скорректированную деформацию (рис. $1, b)$ и топографию (рис. $1, c)$ и, сопоставляя профили на этих АСМ-изображениях. При совпадении максимумов деформации с наклонными участками на профиле топографии считали, что зонд соскальзывает с изучаемого объекта (рис. $1, d$ ). Удовлетворяющие описанному критерию фибробласты относили к разряду скользких, остальные - к категории условно нескользких.

Разделение исследуемых объектов по указанному критерию показало, что у 16 контрольных и 25 культивированных в присутствии колхицина фибробластов есть свидетельства проскальзывания острия зондового датчика на клетке, и таких признаков обнаружить не удалось у 33 контрольных и 25 обработанных исследуемым веществом клеток. При сравнении средних значений модуля Юнга фибробластов с выявленным проскальзыванием АCM-зонда оказалось, что колхицин приводит к росту величины параметра - с $44 \pm 21 \mathrm{kPa}$ (у контрольных) до $61 \pm 41 \mathrm{kPa}$. Аналогично увеличение среднего модуля Юнга под действием субстанции было зарегистрировано и у фибробластов, на которых не обнаруживалось соскальзывание: значения параметра были $31 \pm 19 \mathrm{kPa}$ и $47 \pm 37 \mathrm{kPa}$ у контрольных и обработанных колхицином клеток соответственно. Различия в значениях модуля Юнга в обоих случаях не были статистически значимы по $U$-критерию Манна-Уитни $(p>0.05)$. Несмотря на это, важно, что в разных группах фибробластов эффект колхицина является одинаковым.

Следует отметить, что отсутствие характерных максимумов у границ клеток на АСМ-картах скорректированной деформации не обязательно значит, что контакт между зондом и образцом не является скользким. Во-первых, не все АСМ-изображения фибробластов поддавались предложенному анализу, поскольку некоторые клетки имели недостаточно протяженную границу 

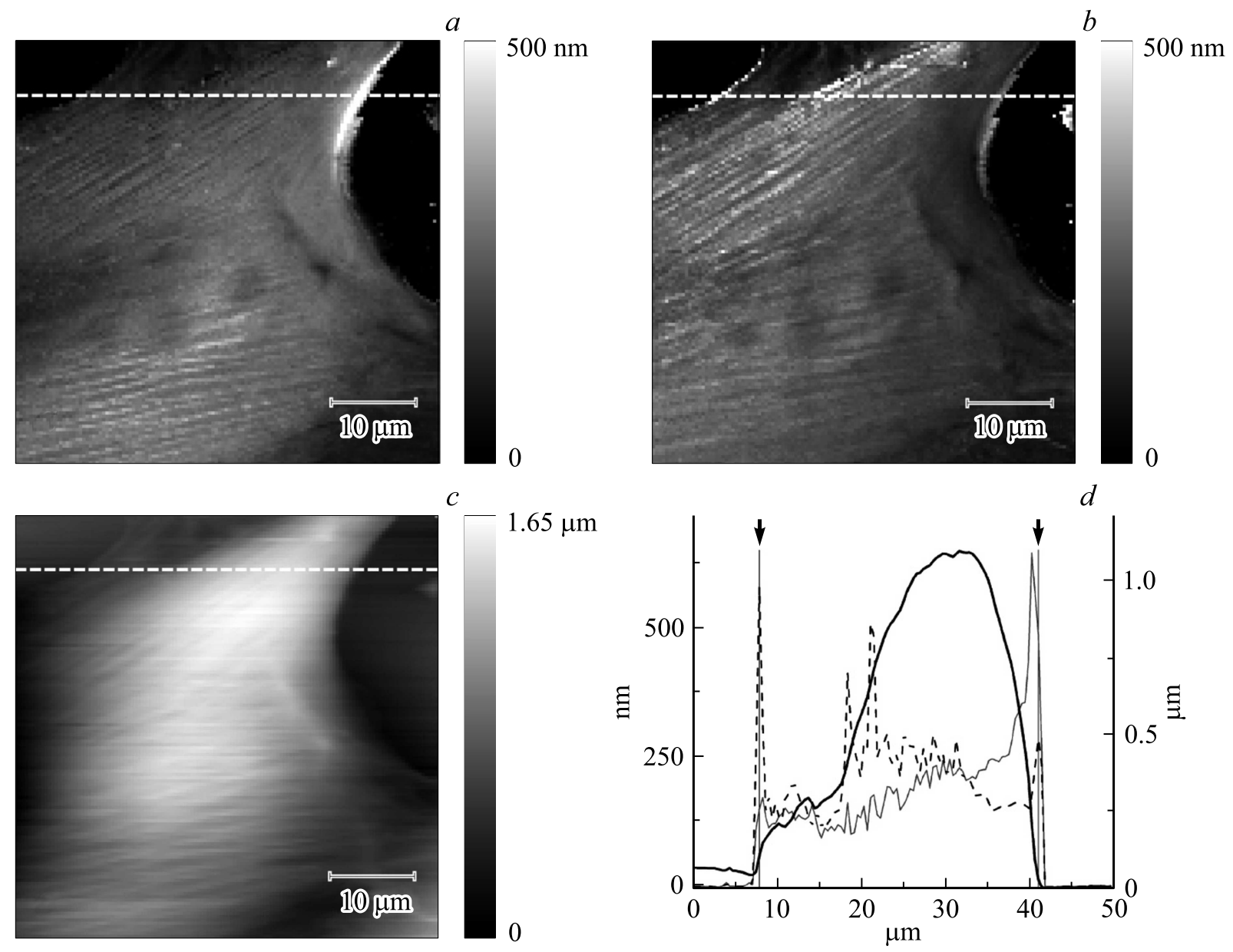

Рис. 1. АСМ-изображения контрольного нативного фибробласта: сигнал деформации экспериментальной $(a)$ и после коррекции $(b)$, учитывающей величину ошибки пиковой силы; $c$ - топография; $d-$ профили деформации и топографии, место их извлечения отмечено пунктирной прямой линией на $(a-c)$, тонкая сплошная и прерывистая линии представляют собой соответственно профили экспериментальной и скорректированной деформации, а жирная сплошная линия соответствует профилю топографии (стрелками отмечены положения пиков скорректированной деформации на краях клетки, они приходятся на значения $\approx 7.8 \mu \mathrm{m}$ и $\approx 41.0 \mu \mathrm{m})$. Приведенные АСМ-изображения получены при сканировании справа налево.

на карте деформации. Во-вторых, часть клеток характеризовалась очень пологими склонами, что мешало проявлению эффекта увеличения амплитуды кажущейся деформации.

Дополнительный анализ АСМ-данных показал, что фибробласты сильно различаются между собой по механическим характеристикам. Одни клетки довольно мягкие, с относительно однородным распределением модуля Юнга по поверхности. У других же, более твердых (рис. 2, $a, b$ ), на картах модуля Юнга отчетливо проявляются жесткие фибриллярные структуры, наличие которых приводит к большему разбросу абсолютных значений параметра. Эти структуры, по-видимому, соответствуют стресс-фибриллам, толстым пучкам актиновых микрофиламентов [13]. Кроме того, фибробласты со стресс-фибриллами, как правило, имели сильно асимметричное распределение модуля Юнга, в то время как форма распределения у мягких клеток была более симметричной (рис. 2, $c, d$ ). Основываясь на предыдущем
Данные по фибробластам двух групп, разделенных по наличию стресс-фибрилл

\begin{tabular}{c|c|c|c}
\hline \multirow{2}{*}{ Группа } & \multirow{2}{*}{$\begin{array}{c}\text { Тип контакта } \\
\text { зонд-образец }\end{array}$} & \multicolumn{2}{|c}{ Средний модуль Юнга, $\mathrm{kPa}$} \\
\cline { 3 - 4 } & & Контроль & Колхицин \\
\hline \multirow{2}{*}{ I } & скользящий & $17 \pm 6(n=3)$ & $24 \pm 8(n=8)$ \\
\cline { 2 - 4 } & нескользящий & $18 \pm 4(n=18)$ & $23 \pm 7(n=13)$ \\
\hline \multirow{2}{*}{ II } & скользящий & $50 \pm 18(n=13)$ & $78 \pm 39(n=17)$ \\
\cline { 2 - 4 } & нескользящий & $46 \pm 18(n=15)$ & $72 \pm 40(n=12)$
\end{tabular}

разделении по типу контакта зонд-образец, действие колхицина было рассмотрено по отдельности для мягких, не имеющих стресс-фибрилл клеток (I группа) и твердых фибробластов со стресс-фибриллами (II группа). Результаты анализа сведены в таблицу. 

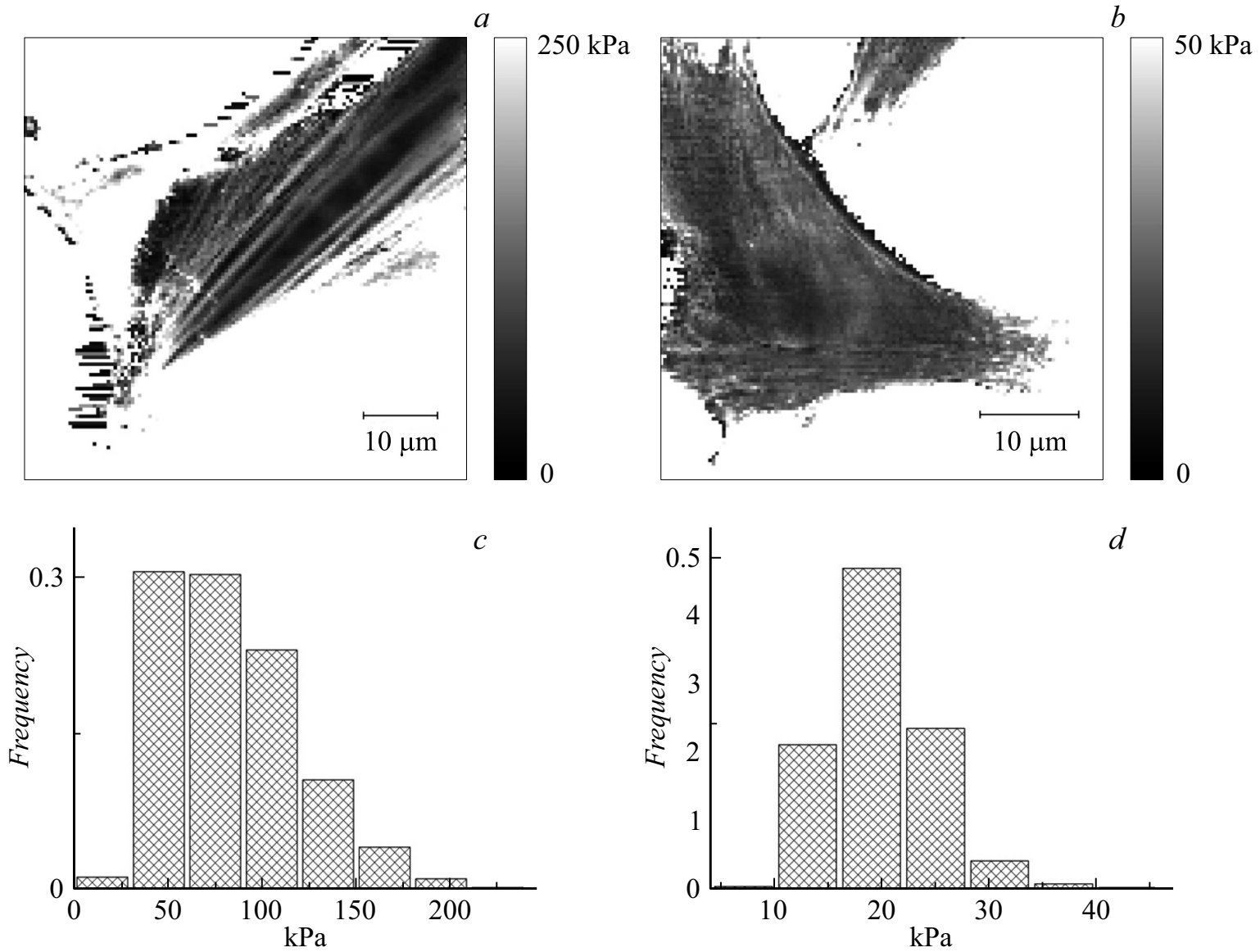

Рис. 2. АСМ-карты кажущегося модуля Юнга контрольных нативных фибробластов со стресс-фибриллами $(a)$, без них $(b)$; $c, d-$ гистограммы значений кажущегося модуля Юнга по поверхности клеток $(a),(b)$ соответственно.

Согласно данным таблицы, колхицин во всех четырех случаях увеличивает средний модуль Юнга фибробластов. Интересно, что тип контакта между зондом и клеткой практически не влияет на измеренный средний модуль Юнга фибробластов. Это аргумент в пользу того, что на всех фибробластах АСМ-зонд проскальзывает при индентировании клетки, включая объекты, на картах деформации которых соответствующих признаков нет. Поэтому объединение выборок клеток со скользящим и условно нескользящим типами контакта зонд-образец представляется оправданным. Тогда в I группе величина модуля Юнга после воздействия колхицина составляет $23 \pm 7 \mathrm{kPa}(n=21)$, а в контрольных клетках $18 \pm 4 \mathrm{kPa}(n=21)$. Во II группе колхицин приводит к существенному увеличению среднего модуля Юнга: с $48 \pm 18 \mathrm{kPa}(n=28)$ до $76 \pm 38 \mathrm{kPa}(n=29)$ для контрольных и обработанных колхицином клеток соответственно. В обоих случаях разница между выборками значений модуля Юнга является статистически значимой по $U$-критерию Манна-Уитни $(p<0.05)$.

Применение метода КЛСМ показало, что под действием колхицина в фибробластах крыс происходит существенное увеличение содержания внутриклеточного $F$-актина. В каждой клетке, как в контроле, так и после воздействия колхицина, измеряли интенсивность флуоресценции $F$-актина в трех областях с одинаковой площадью $\left(13.45 \mu \mathrm{m}^{2}\right)$. Распределение интенсивности в пределах выбранной области подчинялось нормальному закону распределения. Интенсивность флуоресценции актиновых микрофиламентов, культивированных в присутствии изучаемой субстанции фибробластов, составила $25.6 \pm 1.6$ a.u. $(n=45)$, а в контроле лишь $17.7 \pm 2.0$ a.u. $(n=43)$. Различие в интенсивностях было статистически значимым по $t$-критерию Стьюдента $(p<0.05)$. Данный результат объясняет зарегистрированное с помощью АСМ увеличение жесткости фибробластов под действием колхицина.

Следует отметить, что обнаруженный в настоящей работе эффект колхицина $(1 \mu \mathrm{g} / \mathrm{ml})$ на фибробласты крысы аналогичен эффекту от $0.1 \mu \mathrm{g} / \mathrm{ml}$ на нативные фибробласты 10-12-дневных куриных эмбрионов [9]. Как и в [9], тип контакта АCM-зонда с поверхностью клетки не изменял тенденции к увеличению жесткости фибробластов под действием колхицина, что свидетельствует в пользу универсальности эффекта. Это подтверждается и данными КЛСМ, демонстрирующими соответствующее увеличение внутриклеточного содержания фибриллярного актина. 


\section{Заключение}

Было изучено действие колхицина на первичные фибробласты крысы с помощью методов АСМ и КЛСМ. Анализируя АСМ-данные фибробластов, использовали подход, позволяющий идентифицировать проскальзывание АСМ-зонда на поверхности клетки. Это позволило однозначно интерпретировать полученные АСМ-данные. Под действием колхицина был зарегистрирован достоверный рост средних значений кажущегося модуля Юнга как в группе не имеющих стресс-фибрилл, мягких фибробластов, так и в группе более твердых клеток со стресс-фибриллами. В результате изучения фибробластов методом КЛСМ, было продемонстрировано, что под действием колхицина наблюдается рост интенсивности флуоресценции $F$-актина. Таким образом, ингибирующий полимеризацию тубулиновых микротрубочек колхицин запускает в фибробластах механизм компенсаторной реакции, заключающейся в увеличении полимеризации фибриллярного актина.

\section{Благодарности}

Работа выполнена на оборудовании ЦКП „Конфокальная микроскопия“ Института физиологии им. И.П. Павлова РАН.

\section{Финансирование работы}

Работа сотрудников Института физиологии им. И.П. Павлова РАН выполнена при поддержке Российского фонда фундаментальных исследований (проект № 18-015-00079), а также программы фундаментальных научных исследований государственных академий наук на 2013-2020 гг. (ГП-14, раздел 64).

\section{Соблюдение этических стандартов}

Эксперименты были разработаны в соответствии с Директивой Совета Европейских сообществ от 24 ноября 1986 года (86/609/ЕЭС). Местный комитет по уходу и использованию животных Института физиологии им. И.П. Павлова РАН утвердил все экспериментальные методики с животными, разрешение № 12 / 03 (20.04.2018).

\section{Конфликт интересов}

Авторы заявляют, что у них нет конфликта интересов.

\section{Список литературы}

[1] Liu L., Zhang W., Li L., Zhu X., Liu J., Wang X., Song Z., $X u$ H., Wang Z. // J. Biomech. 2018. Vol. 67. P. 84-90. DOI: $10.1016 /$ j.jbiomech.2017.11.018

[2] Jung H.I., Shin I., Park Y.M., Kang K.W., Ha K.-S. // Mol. Cells. 1997. Vol. 7. N 3. P. 431-437.
[3] Rotsch C., Radmacher M. // Biophys. J. 2000. Vol. 78. N 1. P. 520-535. DOI: 10.1016/S0006-3495(00)76614-8

[4] Миронов В.Л. Основы сканирующей зондовой микроскопии: учебное пособие для студентов старших курсов высших учебных заведений. НН.: Институт физики микроструктур, 2004. $114 \mathrm{c}$.

[5] Alexander S., Hellemans C.L., Marti O., Schneir J., Elings V., Hansma P.K., Longmire M., Gurley J. // J. Appl. Phys. 1989. Vol. 65. N 1. P. $164-167$. DOI: $10.1063 / 1.342563$

[6] Fujisawa S., Ohta M., Konishi T., Sugawara Ya., Morita S. // Rev. Sci. Instrum. 1994. Vol. 65. N 3. P. 644-647. DOI: $10.1063 / 1.1145131$

[7] Kawakatsu H., Bleuler H., Saito T., Hiroshi K. // Jpn. J. Appl. Phys. 1995. Vol. 34. Pt. 1. N 6B. P. 3400-3402. DOI: $10.1143 /$ JJAP.34.3400

[8] Ankudinov A.V. // Nanosystems: Phys. Chem. Math. 2019. Vol. 10. N 6. P. 642-653. DOI: $10.17586 / 2220-8054-2019-10-6-642-653$

[9] Тимощук К.И., Халисов М.М., Пеннияйнен В.А., Крылов Б.В., Анкудинов А.В. // Письма в ЖТФ. 2019. Т. 45. Вып. 18. C. 44-47. DOI: $10.21883 / J T F .2020 .11 .49987 .118-20$

[Timoshchuk K.I., Khalisov M.M., Penniyaynen V.A. Krylov B.V., Ankudinov A.V. // Tech. Phys. Lett. 2019. Vol. 45. N 9. P. 947-950.] DOI:10.1134/S1063785019090293]

[10] Автореф. канд. дис. Тимощук К.И. СПб: НИУ ИТМО, 2019. $18 \mathrm{c}$.

[11] Sneddon I. // Int. J. Eng. Sci. 1965. Vol. 3. P. 47-57. DOI: $10.1016 / 0020-7225(65) 90019-4$

[12] Глани C. Медико-биологическая статистика. М.: Практика, 1998. $459 \mathrm{c}$.

[13] Ченщов Ю.С. Цитология с элементами целлюлярной патологии: учебное пособие для университетов и медицинских вузов. М.: Медицинское информационное агентство, 2010. $368 \mathrm{c}$. 